\title{
Influence of Course in Medical Ethics and Law on Career Plans of Medical Students
}

\author{
Shi-Yann Cheng ${ }^{1,4,5}$, Lih-Hwa Lin ${ }^{2,3}$, Chung-Han Kao ${ }^{6}$, Tzu-Min Chan ${ }^{4,6}$ \\ ${ }^{1}$ School of Medicine, China Medical University, Taiwan \\ ${ }^{2}$ Graduate Institute of Chinese Medicine, College of Chinese Medicine, China Medical University, Taiwan \\ ${ }^{3}$ Division of Chinese Medicine, China Medical University Beigang Hospital, Taiwan \\ ${ }^{4}$ Department of Medical Education and Research, China Medical University Beigang Hospital, Taiwan \\ ${ }^{5}$ Obstetrics and Gynecology, China Medical University Beigang Hospital, Taiwan \\ ${ }^{6}$ Anesthesia, China Medical University Beigang Hospital, Taiwan \\ ${ }^{6}$ General Education Center, Taiwan Shoufu University, Taiwan
}

Copyright (C) 2015 by authors, all rights reserved. Authors agree that this article remains permanently open access under the terms of the Creative Commons Attribution License 4.0 International License

\begin{abstract}
Background: The significant increase in medical disputes and lawsuits in recent years in Taiwan has severely affected behavior and ecology in medical practice. For this reason, we designed integrated courses on ethics and law and conducted a questionnaire-based career plan study to understand whether these issues influence their specialty selection process. Method: We randomly selected sixth-year medical students that rotated to our hospital to take an integrated course on medical ethics, laws and regulations, and problem-based learning. The students completed the same questionnaire before and after the course. We used a five-point Likert scale for agreement. In addition to calculating the proportion of agreement, we used paired t-tests in the question items before and after the course at a 0.05 level of significance. A qualitative analysis was also made. Results: This study included 98 medical students, 65 of whom were male, and 33 were female. In terms of reasons for studying medicine, the question item with the highest agreement proportion was "I chose to study medicine because being a doctor will enable me to lead a stable life"; in terms of career plans, it was "I will choose my specialty based on my personal aspirations and interests". On agreement scale, significant increases were presented in "I will choose my specialty based on my personal aspirations and interests" and "I will choose my specialty based on my sense of accomplishment". However, a significant reduction was found in "I will choose my specialty based on quality-of-life considerations". Qualitative analysis indicated that the students learnt that "acquiring good communication skills and fulfilling the obligation to obtain informed consent are the fundamental means of preventing medical disputes". Conclusion: After completing the course, medical students put greater emphasis on personal aptitude, interests, and sense of accomplishment, and less on quality-of-life in choosing a specialty.
\end{abstract}

Keywords Career Plan, Medical Ethics, Medical Law, Integrated Course, Problem-based Learning

\section{Background}

Medical ethics is a branch of bioethics that involves the determination of moral values associated with medical treatments, as well as the norms and principles constraining medical practices. The World Health Organization (WHO) considers the following to be essential aspects of a good medical doctor: an excellent care-giver of patients and their families, a decision-maker that considers what is best for his/her patients, an effective communicator in medical teams and elsewhere, a skilled manager that makes the most of limited resources while adhering to the principle of equity, and a community leader that sets great store by preventive medicine. To achieve these objectives, the World Federation for Medical Education (WFME) established seven core areas for medical education: 1. biomedical and scientific knowledge, 2. clinical skills, 3. clinical decision-making, 4. humanistic care, 4 . medical ethics, 6 . clinical communication, and 7. social and behavioral science. In 1999, the Accreditation Council for Graduate Medical Education (ACGME) also proposed an outcome-oriented education program to instill six competencies in doctors: 1. skills related to patient care, 2. medical knowledge, 3. practice-based learning and improvement, 4. interpersonal and communication skills, 5. professionalism, and 6 . systems-based practice. They requested that associations for various medical specialties explicitly define the six competencies in accordance with their fields and create instruments for skill assessment. ${ }^{[1]}$ Although the competencies proposed by the ACGME were designed to be applicable to medical residents and interns, the American 
Board of Medical Specialties (ABMS) later concurred that these six core competencies also applied to continuing education. ${ }^{[2]}$ Researchers designated these competencies as educational objectives for students of medicine, ${ }^{[3-5]}$ and evaluation processes in teaching hospitals in Taiwan have also begun to include them in the assessment of achievements in postgraduate medical training. The requirements imposed by these two organizations show that humanistic care, medical ethics, professionalism, and clinical communication are now crucial issues in undergraduate medical education. Training and assessment for doctor-patient communication has already received considerable attention in the field of medical education. ${ }^{[6-8]}$ However, in recent years the number of medical disputes and lawsuits in Taiwan has risen significantly. Approximately eight out of ten are criminal cases (patients often threaten criminal litigation so that the doctor/hospital being sued acquiesces to civil compensation), and compensation amounts continue to reach new highs. This severely affects the behavior and ecology in medical practices and proves the importance of managing doctor-patient relationships successfully. Therefore, medical education must respond to these trends and put an increased premium on humanism. However, students' understanding of law and medical ethics bears heavily on the contents and methods of teaching.

The goal of the Systems-Based Practice (SBP) course provided by China Medical University Beigang Hospital (CMUBH) is to help students understand the operation and aims of the healthcare system and how to use available resources to provide optimal healthcare. ${ }^{[9]}$ Since its implementation in 2009, the SBP course has received positive responses from students, who particularly look forward to learning from practical experience associated with medical law and disputes. Therefore, starting in the 2012 school year, additional hours were included for a separate Ethics and Law block to create an opportunity for students to learn and experience clinical doctor-patient communication. The block focused particularly on informed consent and related issues of medical ethics. Therefore, an integrated approach was employed, encompassing discussions on laws and regulations, problem-based learning, and role-playing exercises that enabled students to practice doctor-patient communication in simulated scenarios. ${ }^{[7]}$

To determine whether the course influences the career plans of our students, we designed a questionnaire. The objective was to understand how students choose their future specialty after the course extends their knowledge regarding medical ethics and laws, and doctor-patient communication. The results provide valuable reference for doctor-patient communication course reviews and government medical education policies.

\section{Research Subjects and Methods}

\section{Course Content and Teaching Methods}

The SBP rotational training course offered by CMUBH is implemented in blocks. In accordance with current trends and student needs, the topic of medical disputes was included in September, 2010, and the hours allocated to medical ethics and law were increased in September, 2012, to include a separate Ethics and Law block. The content for each block is based on what the personnel in various hospital departments consider useful knowledge for doctors. The structure of the blocks is flexible and arranged according to the routine operation of each department. The lessons may be lecture-based, case studies or discussion, or be implemented in question-and-answer sessions. The rotational training course lasts two weeks, with one or two four-hour sessions for each block. Table 1 presents a typical course arrangement, including 12 blocks: Nursing, Pharmacy, Radiation, Laboratory Testing, Registration and Cashier, Medical Records, Insurance, Accounting, Hospital Management (including organizational structure, personnel regulations, procurement and storage practices, healthcare quality, patient safety, performance assessment, and administrative decision-making practices), Social/Medical Disputes, Ethics and Law, and Integration. Medical Disputes, Ethics and Law, and Integration span over $0.5,2$, and 2 sessions, respectively, the details of which are as follows.

1. Medical Disputes: This block deals with the means of handling medical disputes and exercises in doctor-patient communication.

2. Ethics and Law: This block is taught by clinical doctors with specialties in ethics or law. An integrated approach is employed to teach medical ethics and law using principles, laws and regulations, problem-based learning (PBL), and clinical cases. Pre-tests and post-tests containing the same ethics and law questions are administered to gauge learning effectiveness.

3. Integration: This is a more flexible block that seven clinical doctors teach by turns. The students are given actual clinical cases in the teacher's specialty and are required to discuss and verify information, whereby they can learn how to use the resources of the healthcare system and provide patients with optimal healthcare. The host of the course also introduces preliminary concepts regarding interprofessional collaborative practice using educational videos to achieve course objectives.

The SBP rotational training course also includes a preliminary introductory block in which the host of the course serves as the instructor. The host gives an introduction to the two-week course and explains the contents and objectives involved. Furthermore, the host is responsible for marking the final reflection reports submitted by the students at the end of the course. 
Table 1. two weeks course paradigm of systems-based practice

\begin{tabular}{|c|c|c|c|c|c|c|}
\hline Week 1 & Monday & Tuesday & Wednesday & Thursday & Friday & Saturday/Sunday \\
\hline $\mathrm{AM}$ & $\begin{array}{l}\text { Orientation / } \\
\text { Introduciton }\end{array}$ & Medical Ethics and Law 1 & Nursing 1 & $\begin{array}{c}\text { Social worker / Medical } \\
\text { disputes }\end{array}$ & Laboratory 1 & \multirow{2}{*}{ Self-study } \\
\hline PM & $\begin{array}{l}\text { Registration and } \\
\text { Cashier }\end{array}$ & Hospital Management 1 & Nursing 2 & Integration 1 & Laboratory 2 & \\
\hline Week 1 & Monday & Tuesday & Wednesday & Thursday & Friday & Saturday/Sunday \\
\hline $\mathrm{AM}$ & Pharmacy1 & Medical Ethics and Law 2 & Insurance & Accounting & Radiation & \multirow[b]{2}{*}{ Self-study } \\
\hline PM & Pharmacy2 & Medical Records & Hospital Management 2 & Integration 2 & $\begin{array}{l}\text { Reflection / } \\
\text { Feedback }\end{array}$ & \\
\hline
\end{tabular}

\section{Research Subjects and Questionnaire Survey}

After being reviewed and ratified by the China Medical University and Hospital Research Ethics Committee, the questionnaire was distributed to 98 sixth-year students that had rotated to our hospital for their clerkship between September, 2011, and April, 2013, 68 of which were majors in medicine and the 30 were double-majoring in medicine and traditional Chinese medicine. The students completed the predesigned career plan questionnaire (Appendix) anonymously (the students were asked to mark the pre- and post- questionnaire with a same two-digit number) before and after the course, thereby enabling us to objectively determine whether the blocks for ethics and law and medical disputes in the SBP rotational training course influenced the career plans of the students.

The questionnaire comprised three portions: the first contained 10 question items on their reasons for studying medicine, the second included 18 question items regarding their future career plans, and the third collected personal information. The 28 question items in the first two portions were measured using a five-point Likert scale with 5 indicating strong agreement and 1 indicating strong disagreement.

\section{Statistical Analysis}

Once the questionnaires were recovered, we first analyzed the proportion of agreement (including agreement and strong agreement) for each question item and performed cross analysis on gender and major using the chi-square test. Subsequently, we analyzed the level of agreement with each question item using mean and standard deviation and tested for differences in opinions and career plans as well as in genders and majors before and after the course using paired t-tests with a 0.05 level of significance. We utilized SPSS 14.0 for Windows to conduct the statistical analyses. Finally, a closing conference was held after the course at which student reflection reports were subjected to qualitative analysis.

\section{Results}

We received valid questionnaires (including pre-course and post-course questionnaires) from a total of 98 sixth-year students majoring in medicine. The subjects included 68 medicine majors and 30 double majors in medicine and traditional Chinese medicine; 65 of the subjects were male, and 33 were female. The ages of the subjects ranged from 22 to 40 , averaging at $25.0 \pm 2.9$ years of age.

Table 2 displays the levels of agreement with the 10 question items in the first portion of the questionnaire before and after the course. The three question items with the highest levels of agreement were "I chose to study medicine because being a doctor will enable me to lead a stable life" $(82.7 \%$ vs. $84.7 \%)$, "I chose to study medicine because being a doctor makes me feel accomplished" (79.6 \% vs. $84.7 \%$ ), and "I chose to study medicine because of my aptitudes and interests" (79.6 \% vs. $79.6 \%)$. Grouping by gender presented differences in "I chose to study medicine because being a doctor makes me feel accomplished" before the course and in "I decided my future based on admission scores" after the course, whereas grouping by major showed no differences before the course but indicated significant differences in "I chose to study medicine because being a doctor will enable me to lead a stable life" after the course.

Table 3 exhibits the levels of agreement with the 18 question items in the second portion of the questionnaire before and after the course. The three question items with the highest levels of agreement were "I will choose my specialty based on my personal aspirations and interests" (94.9\% vs. $99.0 \%$ ), "I will choose my specialty based on my sense of accomplishment" ( $73.5 \%$ vs. $82.7 \%$ ), and "Despite the high prevalence of medical disputes, I will still choose to specialize in one of the five major divisions in emergency and critical care (internal medicine, surgery, gynecology, pediatrics, or emergency medicine)" (74.5\% vs. $79.6 \%$ ). In an additional note, the levels of agreement with "I will not choose one of the five major divisions in emergency and critical care (internal medicine, surgery, gynecology, pediatrics, or emergency medicine) because of the long working hours with many duty calls" before and after the course were $69.4 \%$ and $63.3 \%$, respectively. Grouping by gender presented differences in "I will choose my specialty based on my sense of accomplishment", "I will choose my specialty based on financial considerations", and "I will choose my specialty based on quality-of-life considerations" before the course and in "I will choose my specialty based on my sense of accomplishment" and "I will not choose one of the five major divisions in emergency and critical care (internal medicine, surgery, gynecology, pediatrics, or 
emergency medicine) because of the long working hours with many duty calls" after the course, whereas grouping by major showed differences in "I will choose my specialty based on financial considerations" and "I will choose my specialty based on quality-of-life considerations" before the course but indicated no significant differences after the course.

Table 4 compares the levels of agreement with the 28 question items before and after the course. In terms of reasons for studying medicine, significant increases were shown in the level of agreement with "I chose to study medicine for altruistic reasons" $(3.5 \pm 09$ vs. $3.7 \pm 0.9, \mathrm{p}=$ $0.0067,95 \%$ confidence interval: $0.07 \sim 0.44$ ), "I chose to study medicine because being a doctor makes me feel accomplished" (3.8 \pm 0.9 vs. $4.1 \pm 0.9, \mathrm{p}=0.0012,95 \%$ confidence interval: $0.12 \sim 0.42$ ), "I chose to study medicine because being a doctor enables me to apply my expertise" (3.4 \pm 1.1 vs. $3.8 \pm 0.9, p<0.0001,95 \%$ confidence interval: $0.23 \sim 0.63$ ), "I chose to study medicine because being a

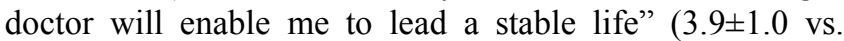
$4.1 \pm 0.9, \mathrm{p}=0.0417,95 \%$ confidence interval: $0.01 \sim 0.42$ ), "I chose to study medicine because doctors are valued by society" $(3.4 \pm 1.0$ vs. $3.7 \pm 1.0, \mathrm{p}=0.0105,95 \%$ confidence interval: $0.07 \sim 0.50$ ), and "I chose to study medicine so that I can do biomedical research in the future" $(2.7 \pm 1.2$ vs. $3.0 \pm 1.2, p=0.0044,95 \%$ confidence interval: $0.12 \sim 0.62$ ). In terms of career plans, significant increases were presented in "I will choose my specialty based on my personal aspirations and interests" ( $4.2 \pm 0.6$ vs. $4.4 \pm 0.5, \mathrm{p}=0.0236$, $95 \%$ confidence interval: $0.02 \sim 0.32$ ) and "I will choose my specialty based on my sense of accomplishment" ( $3.7 \pm 0.9$ vs. $3.9 \pm 0.9, p=0.0193,95 \%$ confidence interval: $0.03 \sim 0.37$ ). However, a significant reduction was found in "I will choose my specialty based on quality-of-life considerations" $(2.8 \pm 1.2$ vs. $2.6 \pm 1.3, \mathrm{p}=0.0357,95 \%$ confidence interval: $-0.35 \sim-0.13$ ).

With regard to the feedback given in the post-course reports, the students gave positive reviews and enthusiastic responses towards the topics of ethics, law, and doctor-patient communication. In the following, we give some examples of the comments made: "I was deeply impressed by the medical dispute course. Disputes rarely occur out of the blue; there are always telltale signs beforehand. If doctors show family members more concern and patience and explain things in more detail, disputes will almost never happen." "The case examples given in class were quite useful. Those of us who were more intimidated by choosing our specialty and the risks of practicing medicine are now progressing toward our goals because we know that we cannot abandon our ideals." "Learning how to deal with medical disputes, comfort patients, and master the art of communication in simulations of real circumstances will be very helpful in our future practice." "Another emphasis of the law course is the importance of communication and its four major elements: verbal language, body language, tone of voice, and eye contact." "The medical ethics course was somewhat different from other normally rigid courses. Of course, we learned about the fundamental concepts and structure of medical ethics, but we were also given many case examples and some basic principles on how to deal with them. We would never have thought of these on our own, and so I believe that what we learned in this course will prove infinitely useful during our medical careers in the future." These comments show how inspirational the course has been to the students. 
Table 2. The reason of studying medicine

\begin{tabular}{|c|c|c|c|c|c|c|c|c|c|c|c|c|c|c|}
\hline \multirow{2}{*}{$\begin{array}{c}\text { serial } \\
\text { number }\end{array}$} & \multicolumn{2}{|c|}{ the percentage of agreement } & \multicolumn{3}{|c|}{ before course grouped by gender } & \multicolumn{3}{|c|}{ after course grouped by gender } & \multicolumn{3}{|c|}{ before course grouped by major } & \multicolumn{3}{|c|}{ after course grouped by major } \\
\hline & before course & after course & female $(n=33)$ & male $(n=65)$ & $\mathbf{p}$ & female $(n=33)$ & male $(n=65)$ & $\mathbf{p}$ & medicine $(n=68)$ & TC medicine $(n=30)$ & $\mathbf{p}$ & medicine $(n=68)$ & TC medicine $(\mathbf{n}=30)$ & $\mathbf{p}$ \\
\hline Q1 & $79.6 \%$ & $79.6 \%$ & $84.90 \%$ & $76.90 \%$ & $0.3576^{\mathrm{C}}$ & $81.80 \%$ & $78.50 \%$ & $0.6968^{\mathrm{C}}$ & $75.00 \%$ & $90.00 \%$ & $0.1084^{\mathrm{F}}$ & $76.50 \%$ & $86.70 \%$ & $0.2902^{\mathrm{F}}$ \\
\hline Q2 & $36.7 \%$ & $44.9 \%$ & $27.30 \%$ & $41.50 \%$ & $0.1662^{\mathrm{C}}$ & $33.30 \%$ & $50.80 \%$ & $0.1010^{\mathrm{C}}$ & $42.70 \%$ & $23.30 \%$ & $0.0676^{\mathrm{C}}$ & $50.00 \%$ & $33.30 \%$ & $0.1263^{\mathrm{C}}$ \\
\hline Q3 & $43.9 \%$ & $41.8 \%$ & $48.50 \%$ & $41.50 \%$ & $0.5125^{\mathrm{C}}$ & $27.30 \%$ & $49.20 \%$ & $0.0373^{\mathrm{C}^{*}}$ & $48.50 \%$ & $33.30 \%$ & $0.1624^{C}$ & $45.60 \%$ & $33.30 \%$ & $0.2570^{C}$ \\
\hline Q4 & $60.2 \%$ & $74.5 \%$ & $51.50 \%$ & $64.60 \%$ & $0.2105^{\mathrm{C}}$ & $69.70 \%$ & $76.90 \%$ & $0.4380^{\mathrm{C}}$ & $55.90 \%$ & $70.00 \%$ & $0.1882^{\mathrm{C}}$ & $70.60 \%$ & $83.30 \%$ & $0.1822^{\mathrm{C}}$ \\
\hline Q5 & $79.6 \%$ & $84.7 \%$ & $66.70 \%$ & $86.20 \%$ & $0.0237^{C^{*}}$ & $75.80 \%$ & $89.20 \%$ & $0.0800^{\mathrm{C}}$ & $77.90 \%$ & $83.30 \%$ & $0.5416^{\mathrm{C}}$ & $80.90 \%$ & $93.30 \%$ & $0.1390^{\mathrm{F}}$ \\
\hline Q6 & $60.2 \%$ & $75.5 \%$ & $60.60 \%$ & $60.00 \%$ & $0.9538^{\mathrm{C}}$ & $66.70 \%$ & $80.00 \%$ & $0.1469^{\mathrm{C}}$ & $54.40 \%$ & $73.30 \%$ & $0.0778^{\mathrm{C}}$ & $70.60 \%$ & $86.70 \%$ & $0.1261^{\mathrm{F}}$ \\
\hline Q7 & $82.7 \%$ & $84.7 \%$ & $81.80 \%$ & $83.10 \%$ & $0.8764^{\mathrm{C}}$ & $81.80 \%$ & $86.20 \%$ & $0.5732^{\mathrm{C}}$ & $77.90 \%$ & $93.30 \%$ & $0.0839^{\mathrm{F}}$ & $79.40 \%$ & $96.70 \%$ & $0.0332^{\mathrm{F}^{*}}$ \\
\hline Q8 & $66.3 \%$ & $73.5 \%$ & $54.60 \%$ & $72.30 \%$ & $0.0787^{\mathrm{C}}$ & $63.60 \%$ & $78.50 \%$ & $0.1162^{\mathrm{C}}$ & $66.20 \%$ & $66.70 \%$ & $0.9623^{\mathrm{C}}$ & $70.60 \%$ & $80.00 \%$ & $0.3307^{\mathrm{C}}$ \\
\hline Q9 & $40.8 \%$ & $46.9 \%$ & $27.30 \%$ & $47.70 \%$ & $0.0519^{\mathrm{C}}$ & $36.40 \%$ & $52.30 \%$ & $0.1350^{\mathrm{C}}$ & $47.10 \%$ & $26.70 \%$ & $0.0584^{\mathrm{C}}$ & $48.50 \%$ & $43.30 \%$ & $0.6348^{\mathrm{C}}$ \\
\hline Q10 & $29.6 \%$ & $44.9 \%$ & $24.20 \%$ & $32.30 \%$ & $0.4084^{\mathrm{C}}$ & $39.40 \%$ & $47.70 \%$ & $0.4351^{\mathrm{C}}$ & $30.90 \%$ & $26.70 \%$ & $0.6735^{\mathrm{C}}$ & $44.10 \%$ & $46.70 \%$ & $0.8151^{\mathrm{C}}$ \\
\hline
\end{tabular}

TC medicine: double-majoring in medicine and tradtional Chinese medicine

${ }^{\mathrm{F}}$ Fisher's exact test, ${ }^{\mathrm{c}}$ chi-squared test comparing subjects

${ }^{*}$ p-vale $<0.05 * *$ p-vale $<0.01 * * * \mathrm{p}$-vale $<0.001$

\begin{tabular}{|c|c|c|c|c|c|c|c|c|c|c|c|c|c|c|}
\hline \multirow{2}{*}{$\begin{array}{c}\text { serial } \\
\text { number }\end{array}$} & \multicolumn{2}{|c|}{ the percentage of agreement } & \multicolumn{3}{|c|}{ before course grouped by gender } & \multicolumn{3}{|c|}{ after course grouped by gender } & \multicolumn{3}{|c|}{ before course grouped by major } & \multicolumn{3}{|c|}{ after course grouped by major } \\
\hline & before course & after course & female $(n=33)$ & male $(n=65)$ & $\mathbf{p}$ & female $(n=33)$ & male $(n=65)$ & $\mathbf{p}$ & medicine $(n=68)$ & TC medicine $(\mathrm{n}=30)$ & p & medicine $(n=68)$ & TC medicine $(n=30)$ & $\mathbf{p}$ \\
\hline Q11 & $69.4 \%$ & $73.5 \%$ & $63.60 \%$ & $72.30 \%$ & $0.3787^{\mathrm{C}}$ & $69.70 \%$ & $75.40 \%$ & $0.5467^{\mathrm{C}}$ & $70.60 \%$ & $66.70 \%$ & $0.8126^{\mathrm{C}}$ & $75.00 \%$ & $70.00 \%$ & $0.6054^{\mathrm{C}}$ \\
\hline Q12 & $94.9 \%$ & $99.0 \%$ & $90.90 \%$ & $96.90 \%$ & $0.3314^{\mathrm{F}}$ & $97.00 \%$ & $100.00 \%$ & $0.3367^{\mathrm{F}}$ & $95.60 \%$ & $93.30 \%$ & $0.6402^{\mathrm{F}}$ & $98.50 \%$ & $100.00 \%$ & $1.0000^{\mathrm{F}}$ \\
\hline Q13 & $73.5 \%$ & $82.7 \%$ & $60.60 \%$ & $80.00 \%$ & $0.0399^{\mathrm{C}^{*}}$ & $69.70 \%$ & $89.20 \%$ & $0.0158^{\mathrm{C}^{*}}$ & $70.60 \%$ & $80.00 \%$ & $0.3307^{\mathrm{C}}$ & $80.90 \%$ & $86.70 \%$ & $0.5739^{\mathrm{F}}$ \\
\hline Q14 & $35.7 \%$ & $37.8 \%$ & $21.20 \%$ & $43.10 \%$ & $0.0328^{\mathrm{C}^{*}}$ & $30.30 \%$ & $41.50 \%$ & $0.2782^{\mathrm{C}}$ & $42.70 \%$ & $20.00 \%$ & $0.0311^{\mathrm{C}^{*}}$ & $42.70 \%$ & $26.70 \%$ & $0.1326^{\mathrm{C}}$ \\
\hline Q15 & $36.7 \%$ & $33.7 \%$ & $18.20 \%$ & $46.20 \%$ & $0.0066^{\mathrm{C}^{* *}}$ & $21.20 \%$ & $40.00 \%$ & $0.0629^{\mathrm{C}}$ & $44.10 \%$ & $20.00 \%$ & $0.0225^{\mathrm{C}^{*}}$ & $39.70 \%$ & $20.00 \%$ & $0.0571^{C}$ \\
\hline Q16 & $45.9 \%$ & $46.9 \%$ & $54.60 \%$ & $41.50 \%$ & $0.2220^{\mathrm{C}}$ & $45.50 \%$ & $47.70 \%$ & $0.8338^{\mathrm{C}}$ & $45.60 \%$ & $46.70 \%$ & $0.9213^{\mathrm{C}}$ & $42.70 \%$ & $56.70 \%$ & $0.2000^{\mathrm{C}}$ \\
\hline Q17 & $44.9 \%$ & $43.9 \%$ & $54.60 \%$ & $40.00 \%$ & $0.1713^{\mathrm{C}}$ & $54.60 \%$ & $38.50 \%$ & $0.1294^{\mathrm{C}}$ & $47.10 \%$ & $40.00 \%$ & $0.5173^{\mathrm{C}}$ & $45.60 \%$ & $40.00 \%$ & $0.6074^{\mathrm{C}}$ \\
\hline Q18 & $45.9 \%$ & $50.0 \%$ & $51.50 \%$ & $43.10 \%$ & $0.4282^{\mathrm{C}}$ & $54.60 \%$ & $47.70 \%$ & $0.5214^{\mathrm{C}}$ & $45.60 \%$ & $46.70 \%$ & $0.9213^{\mathrm{C}}$ & $47.10 \%$ & $56.70 \%$ & $0.3806^{\mathrm{C}}$ \\
\hline Q19 & $52.0 \%$ & $49.0 \%$ & $63.60 \%$ & $46.20 \%$ & $0.1016^{\mathrm{C}}$ & $57.60 \%$ & $44.60 \%$ & $0.2252^{\mathrm{C}}$ & $52.90 \%$ & $50.00 \%$ & $0.7882^{\mathrm{C}}$ & $48.50 \%$ & $50.00 \%$ & $0.8932^{\mathrm{C}}$ \\
\hline Q20 & $48.0 \%$ & $48.0 \%$ & $54.60 \%$ & $44.60 \%$ & $0.3524^{\mathrm{C}}$ & $54.60 \%$ & $44.60 \%$ & $0.3524^{\mathrm{C}}$ & $44.10 \%$ & $56.70 \%$ & $0.2518^{\mathrm{C}}$ & $45.60 \%$ & $53.30 \%$ & 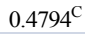 \\
\hline Q21 & $57.1 \%$ & $44.9 \%$ & $69.70 \%$ & $50.80 \%$ & $0.0736^{\mathrm{C}}$ & $51.50 \%$ & $41.50 \%$ & $0.3480^{\mathrm{C}}$ & $58.80 \%$ & $53.30 \%$ & $0.6127^{\mathrm{C}}$ & $44.10 \%$ & $46.70 \%$ & $0.8151^{\mathrm{C}}$ \\
\hline Q22 & $48.0 \%$ & $42.9 \%$ & $60.60 \%$ & $41.50 \%$ & $0.0742^{\mathrm{C}}$ & $45.50 \%$ & $41.50 \%$ & $0.7112^{\mathrm{C}}$ & $48.50 \%$ & $46.70 \%$ & $0.8649^{\mathrm{C}}$ & $41.20 \%$ & $46.70 \%$ & $0.6127^{\mathrm{C}}$ \\
\hline Q23 & $43.9 \%$ & $45.9 \%$ & $57.60 \%$ & $36.90 \%$ & $0.0515^{\mathrm{C}}$ & $57.60 \%$ & $40.00 \%$ & $0.0989^{\mathrm{C}}$ & $42.70 \%$ & $46.70 \%$ & $0.7117^{\mathrm{C}}$ & $41.20 \%$ & $56.70 \%$ & $0.1561^{\mathrm{C}}$ \\
\hline Q24 & $34.7 \%$ & $42.9 \%$ & $36.40 \%$ & $33.90 \%$ & $0.8046^{\mathrm{C}}$ & $39.40 \%$ & $44.60 \%$ & $0.6216^{\mathrm{C}}$ & $39.70 \%$ & $23.30 \%$ & $0.1166^{\mathrm{C}}$ & $45.60 \%$ & $36.70 \%$ & $0.4108^{\mathrm{C}}$ \\
\hline Q25 & $57.1 \%$ & $54.1 \%$ & $60.60 \%$ & $55.40 \%$ & $0.6216^{\mathrm{C}}$ & $45.50 \%$ & $58.50 \%$ & $0.2220^{\mathrm{C}}$ & $60.30 \%$ & $50.00 \%$ & $0.3426^{\mathrm{C}}$ & $54.40 \%$ & $53.30 \%$ & $0.9213^{\mathrm{C}}$ \\
\hline Q26 & $69.4 \%$ & $63.3 \%$ & $72.70 \%$ & $67.70 \%$ & $0.6093^{\mathrm{C}}$ & $48.50 \%$ & $70.80 \%$ & $0.0306^{\mathrm{C}^{*}}$ & $73.50 \%$ & $60.00 \%$ & $0.1805^{\mathrm{C}}$ & $67.70 \%$ & $53.30 \%$ & $0.1755^{\mathrm{C}}$ \\
\hline Q27 & $74.5 \%$ & $79.6 \%$ & $69.70 \%$ & $76.90 \%$ & $0.4380^{\mathrm{C}}$ & $75.80 \%$ & $81.50 \%$ & $0.5022^{\mathrm{C}}$ & $77.90 \%$ & $66.70 \%$ & $0.2380^{\mathrm{C}}$ & $79.40 \%$ & $80.00 \%$ & $0.9469^{\mathrm{C}}$ \\
\hline Q28 & $41.8 \%$ & $32.7 \%$ & $42.40 \%$ & $41.50 \%$ & $0.9330^{\mathrm{C}}$ & $36.40 \%$ & $30.80 \%$ & $0.5768^{\mathrm{C}}$ & $42.70 \%$ & $40.00 \%$ & $0.8066^{\mathrm{C}}$ & $32.40 \%$ & $33.30 \%$ & $0.9240^{\mathrm{C}}$ \\
\hline
\end{tabular}

TC medicine: double-majoring in medicine and tradtional Chinese medicine

${ }^{\mathrm{F}}$ Fisher's exact test, ${ }^{\mathrm{c}}$ chi-squared test comparing subjects

$*$ p-vale $<0.05 \quad * *$ p-vale $<0.01 \quad * * *$ p-vale $<0.001$ 
Table 4. Agreement scale comparsion

\begin{tabular}{|c|c|c|c|c|}
\hline serial number & before course & after course & 95\% CI of change & $\mathbf{p}$ \\
\hline Q1 & $3.9 \pm 0.9$ & $3.9 \pm 1.0$ & $(-0.13,0.18)$ & 0.7944 \\
\hline Q2 & $2.7 \pm 1.3$ & $2.9 \pm 1.3$ & $(-0.05,0.35)$ & 0.1324 \\
\hline Q3 & $2.9 \pm 1.3$ & $2.8 \pm 1.3$ & $(-0.31,0.20)$ & 0.6863 \\
\hline Q4 & $3.5 \pm 0.9$ & $3.7 \pm 0.9$ & $(0.07,0.44)$ & $0.0067 * *$ \\
\hline Q5 & $3.8 \pm 0.9$ & $4.1 \pm 0.9$ & $(0.12,0.46)$ & $0.0012 * *$ \\
\hline Q6 & $3.4 \pm 1.1$ & $3.8 \pm 0.9$ & $(0.23,0.63)$ & $<0.0001 * * *$ \\
\hline Q7 & $3.9 \pm 1.0$ & $4.1 \pm 0.9$ & $(0.01,0.42)$ & $0.0417^{*}$ \\
\hline Q8 & $3.4 \pm 1.0$ & $3.7 \pm 1.0$ & $(0.07,0.50)$ & $0.0105^{*}$ \\
\hline Q9 & $2.9 \pm 1.2$ & $2.9 \pm 1.2$ & $(-0.21,0.29)$ & 0.7458 \\
\hline Q10 & $2.7 \pm 1.2$ & $3.0 \pm 1.2$ & $(0.12,0.62)$ & $0.0044 * *$ \\
\hline Q11 & $3.6 \pm 0.8$ & $3.8 \pm 0.8$ & $(-0.01,0.34)$ & 0.0590 \\
\hline Q12 & $4.2 \pm 0.6$ & $4.4 \pm 0.5$ & $(0.02,0.32)$ & $0.0236^{*}$ \\
\hline Q13 & $3.7 \pm 0.9$ & $3.9 \pm 0.9$ & $(0.03,0.37)$ & $0.0193^{*}$ \\
\hline Q14 & $2.9 \pm 1.0$ & $2.7 \pm 1.1$ & $(-0.31,0.09)$ & 0.2662 \\
\hline Q15 & $2.8 \pm 1.2$ & $2.6 \pm 1.3$ & $(-0.35,-0.01)$ & $0.0357^{*}$ \\
\hline Q16 & $3.2 \pm 1.0$ & $3.2 \pm 1.0$ & $(-0.25,0.19)$ & 0.7794 \\
\hline Q17 & $3.3 \pm 1.2$ & $3.2 \pm 1.0$ & $(-0.27,0.12)$ & 0.4707 \\
\hline Q18 & $3.3 \pm 1.1$ & $3.3 \pm 1.1$ & $(-0.22,0.20)$ & 0.9229 \\
\hline Q19 & $3.3 \pm 1.1$ & $3.2 \pm 1.0$ & $(-0.24,0.14)$ & 0.5945 \\
\hline Q20 & $3.2 \pm 1.1$ & $3.2 \pm 1.0$ & $(-0.24,0.18)$ & 0.7692 \\
\hline Q21 & $3.4 \pm 1.0$ & $3.2 \pm 1.0$ & $(-0.43,0.00)$ & 0.0517 \\
\hline Q22 & $3.2 \pm 1.0$ & $3.1 \pm 0.9$ & $(-0.34,0.13)$ & 0.3868 \\
\hline Q23 & $3.2 \pm 1.1$ & $3.2 \pm 1.0$ & $(-0.16,0.24)$ & 0.6821 \\
\hline Q24 & $3.1 \pm 1.0$ & $3.4 \pm 1.0$ & $(-0.06,0.36)$ & 0.4473 \\
\hline Q25 & $3.4 \pm 1.2$ & $3.3 \pm 1.2$ & $(-0.39,0.14)$ & 0.3657 \\
\hline Q26 & $3.7 \pm 1.1$ & $3.6 \pm 1.1$ & $(-0.38,0.17)$ & 0.4614 \\
\hline Q27 & $3.7 \pm 0.9$ & $3.9 \pm 0.9$ & $(-0.07,0.41)$ & 0.1532 \\
\hline Q28 & $3.0 \pm 1.1$ & $2.9 \pm 1.0$ & $(-0.42,0.06)$ & 0.1316 \\
\hline
\end{tabular}

Likert scale: 5 strong agree; 4 agree; 3 neither agree or disagree; 2 disagree; 1 strong disagree data: mean \pm standard deviation paired $t$ test comparing subjects between pre-test and post-test.

$*$ : p-value $<0.05 * *:$ p-value $<0.01 * * *:$ p-value $<0.001$ 


\section{Discussion}

Human rights organizations around the world advocate autonomy in medicine with one accord, and democratic progress in Taiwan has also promoted the establishment of medical human rights. This has led to a substantial increase in the number of medical disputes and lawsuits in Taiwan in recent years. Compensation amounts increase continue to increase, severely affecting the behavior and ecology in medical practices in Taiwan and making medical students less willing to choose risky specialties in critical care. With such increasingly tense doctor-patient relationships and doctors possibly facing criminal litigations at any moment, Common Health Magazine (2012; 164: 144-153) warned of a severe collapse in medical care in Taiwan. The investigation conducted revealed that only approximately 800 obstetricians in Taiwan are still willing to deliver babies and that 159 rural communities had no obstetricians for delivery service. In spite of the occurrence of enterovirus epidemics, 132 rural communities have no pediatricians, and emergency and critical care specialists are stretched thin. Two out of ten doctors are serving at weight loss and medical cosmetic centers, preferring to cater to patients' superficial medical needs rather than save lives. Wealth Magazine (2012; 408: 78-85) surveyed fifth-year and sixth-year medical students at National Taiwan University and discovered that $30 \%$ of the students questioned their own choice of specialty. This is not only an issue of ethics and law in medical education but also a healthcare environment issue that Taiwan must face. The changes in the healthcare environment in Taiwan have made it difficult for hospitals to recruit physicians, surgeons, obstetrician/gynecologist, pediatricians, and emergency physicians, thereby leading to a continuing decline in the number of physicians. The Ministry of Health and Welfare perceived this potential threat from the average recruitment rates in various specialties in the last few years and responded by formulating the Subsidy Program for Key Specialty Residents. Implemented on September 1, 2013, the program subsidizes the training of residents in these five major specialties, but its effectiveness remains to be seen. Establishing a medical environment that provides humanistic healthcare and promotes harmony between doctors and patients is also a means to ameliorate the decline in critical care professionals. The SBP course in our hospital, which includes a reinforced practical course for clinical doctor-patient communication, is therefore well-suited to student needs and current trends. By analyzing the questionnaires completed by students before and after the course and the closing conferences and reflection reports, we determined that doctor-patient communication education based on medical ethics and law is capable of changing the way medical students feel about their choice of specialty.

International research shows that when residents in training are choosing their specialty, the influences on their decision include future quality of life, the medical environment, and the people in it. ${ }^{[10-12]} \mathrm{A}$ review of recent criminal cases in Taiwan involving medical disputes indicates that what doctors most urgently need to know about is informed consent. To this end, clinical case examples were specially compiled into PBL lesson plans and taught using an integrated approach, encompassing discussions on laws and regulations and role-playing exercises that enabled students to practice doctor-patient communication in simulated scenarios. These methods gave students a deeper and more practical understanding of medical ethics, humanistic care, and clinical communication. Analysis of the questionnaire results indicates that after taking the course, students feel more confident in their choice to study medicine for altruistic reasons, their own sense of accomplishment, the application of their expertise, quality of life and to be valued by society. Of these, most consideration was given to their aptitudes, interests, and sense of accomplishment. The qualitative feedback from the closing conferences and reflection reports also shows that the students highly approve of the course and give it positive reviews. During the course, they learnt that "acquiring good communication skills and fulfilling the obligation to obtain informed consent are the fundamental means of preventing medical disputes." These analysis results reveal that it would prove worthwhile to extend the contents and methods of the course under study.

Although this course prompts students to contemplate how they can provide humanistic care and fulfill their obligation to obtain informed consent, whether it will have a long-term effect remains to be seen. The effectiveness of changing the behavior of individuals through education can only be proved using follow-up behavioral evaluations. ${ }^{[13-15]}$ After the subjects of this study graduate and begin their general medical training, we can use a 360-degree assessment and the students' choice of specialty to perform a more profound behavioral analysis. We can also investigate changes in medical operation effectiveness and doctor-patient interactions. Although this type of medical education and training has rarely received significant attention in Taiwan in the past, we believe that it is set to soon become a valued approach in the field.

\section{Conclusions}

The results of this study show that after medical students receive practical education on medical ethics and law, the influence of their own aptitudes, interests, and sense of accomplishment on their choice of specialty increases, whereas the influence of quality-of-life considerations declines. However, common medical disputes and the long working hours with many duty calls of specialties in emergency and critical care remain influential factors effecting medical students choice of specialty.

\section{Acknowledgements}

The authors acknowledged the research fund supported by China Medical University Beigang Hospital. This study was approved by the Research Ethics Committee of China Medical University and Hospital (CMUH102-REC02-059, approved June 27, 2013). 


\section{Appendix Questionnaire}

\section{Part I. The Reason of Study Medicine}

Many various factors may affect you to choose department of medicine. According to your real situation, check an option that best matches your experience. Please pay attention to each question should be answered.

\begin{tabular}{|c|c|c|c|c|c|c|}
\hline $\begin{array}{l}\text { Serial } \\
\text { Number }\end{array}$ & Question Items & $\begin{array}{l}\text { Strong } \\
\text { agree }\end{array}$ & Agree & $\begin{array}{c}\text { Neither agree } \\
\text { or disagree }\end{array}$ & Disagree & $\begin{array}{c}\text { Strong } \\
\text { disagree }\end{array}$ \\
\hline Q1 & I chose to study medicine because of my aptitudes and interests & & & & & \\
\hline Q2 & I chose to study medicine because of the decision affected by parents or relatives & & & & & \\
\hline Q3 & I chose to study medicine because of admission scores & & & & & \\
\hline Q4 & I chose to study medicine for altruistic reasons & & & & & \\
\hline Q5 & I chose to study medicine because being a doctor makes me feel accomplished & & & & & \\
\hline Q6 & $\begin{array}{l}\text { I chose to study medicine because being a doctor will enable me to apply my } \\
\text { expertise }\end{array}$ & & & & & \\
\hline Q7 & I chose to study medicine because being a doctor will enable me to lead a stable life & & & & & \\
\hline Q8 & I chose to study medicine because doctors are valued by society & & & & & \\
\hline Q9 & I chose to study medicine because being a doctor will enable me to have rich income & & & & & \\
\hline Q10 & I chose to study medicine so that I can do biomedical research in the future & & & & & \\
\hline
\end{tabular}

\section{Part II. Future Career Plans}

Specialty choice may change over time, environment, experience. According to your real situation, check an option that best matches your experience. Please pay attention to each question should be answered.

\begin{tabular}{|c|c|c|c|c|c|c|}
\hline $\begin{array}{c}\text { Serial } \\
\text { Number }\end{array}$ & Items & \begin{tabular}{c|c} 
Strong \\
agree
\end{tabular} & Agree & \begin{tabular}{|c|}
$\begin{array}{c}\text { Neither agree } \\
\text { or disagree }\end{array}$ \\
\end{tabular} & Disagree & $\begin{array}{c}\text { Strong } \\
\text { disagree }\end{array}$ \\
\hline Q11 & $\begin{array}{l}\text { I will choose to specialize in any one of the five major divisions in emergency and } \\
\text { critical care (internal medicine, surgery, gynecology, pediatrics, or emergency } \\
\text { medicine) }\end{array}$ & & & & & \\
\hline Q12 & I will choose my specialty based on my personal aspirations and interests & & & & & \\
\hline Q13 & I will choose my specialty based on my sense of accomplishment & & & & & \\
\hline Q14 & I will choose my specialty based on financial considerations & & & & & \\
\hline Q15 & I will choose my specialty based on quality-of-life considerations & & & & & \\
\hline Q16 & $\begin{array}{l}\text { I will choose to continue studying in non-clinical graduate institute such as basic } \\
\text { medicine or public health to be engaged in academic research and teaching }\end{array}$ & & & & & \\
\hline Q17 & I will choose to work in non-clinical area such as literature creation & & & & & \\
\hline Q18 & I will choose to work in non-clinical area such as music creation & & & & & \\
\hline Q19 & $\begin{array}{l}\text { I will choose to work in non-clinical area such as marketing of pharmaceutical agents } \\
\text { and medical devices }\end{array}$ & & & & & \\
\hline Q20 & $\begin{array}{l}\text { I will choose to work in non-clinical area such as business administration and } \\
\text { management }\end{array}$ & & & & & \\
\hline Q21 & $\begin{array}{l}\text { I will choose to work in non-clinical area such as medical administration and } \\
\text { management }\end{array}$ & & & & & \\
\hline Q22 & I will choose to work in non-clinical area such as medical lawyer & & & & & \\
\hline Q23 & I will choose to work in non-clinical area such as basic medicine research & & & & & \\
\hline Q24 & $\begin{array}{l}\text { I will choose to specialize in none of the five major divisions in emergency and critical } \\
\text { care (internal medicine, surgery, gynecology, pediatrics, or emergency medicine) }\end{array}$ & & & & & \\
\hline Q25 & $\begin{array}{l}\text { I will not choose any one of the five major divisions in emergency and critical care } \\
\text { (internal medicine, surgery, gynecology, pediatrics, or emergency medicine) because } \\
\text { of high prevalence of medical disputes and none people's respect for doctor in Taiwan }\end{array}$ & & & & & \\
\hline Q26 & $\begin{array}{l}\text { I will not choose any one of the five major divisions in emergency and critical care } \\
\text { (internal medicine, surgery, gynecology, pediatrics, or emergency medicine) because } \\
\text { of the long working hours with many duty calls }\end{array}$ & & & & & \\
\hline Q27 & $\begin{array}{l}\text { Despite the high prevalence of medical disputes, I will still choose to specialize in any } \\
\text { one of the five major divisions in emergency and critical care (internal medicine, } \\
\text { surgery, gynecology, pediatrics, or emergency medicine) }\end{array}$ & & & & & \\
\hline Q28 & $\begin{array}{l}\text { I will choose to specialize in any one of the five major divisions in emergency and } \\
\text { critical care (internal medicine, surgery, gynecology, pediatrics, or emergency } \\
\text { medicine) and consider practicing in foreign countries such as Singapore, U.S.A., or } \\
\text { Australia. }\end{array}$ & & & & & \\
\hline
\end{tabular}




\section{Part III. Basic Data}

Gender: $\square$ male $\square$ female

Age: years

Major: $\square$ Medicine $\square$ Double-major in Medicine and Traditional Chinese Medicine

\section{REFERENCES}

[1] Accreditation Council for Graduate Educatin: ACGME Outcomes Project. 2005. (Accessed March 30, 2005, at http://www.acgme.org/outcome/.)

[2] American Board of Medical Specialties: Maintenance of Certification (MOC) Competencies and Criteria 2007. (Accessed October 2, 2007, at http://www.abms.org/Mainten ance_of_Certification/MOC_competencies.aspx.)

[3] Rabinowitz HK, Babbott D, Bastacky S, et al: Innovative approaches to educating medical students for practice in a changing health care environment: the National UME-21 Project. Acad Med 2001;76:587-97.

[4] Pascoe JM, Babbott D, Pye KL, et al: The UME-21 project: connecting medical education and medical practice. Fam Med 2004;36 Supp1:S12-4.

[5] Colbert CY, Ogden PE, Lowe D, et al: Students learn systems-based care and facilitate system change as stakeholders in a free clinic experience. Adv Health Sci Educ Theory Pract 2010;15:533-45.

[6] Rider EA, Hinrichs MM, Lown BA. A model for communication skills assessment across the undergraduate curriculum. Med Teach 2006;28:e127-34.

[7] Watmough S, Garden A, Taylor D. Does a new integrated PBL curriculum with specific communication skills classes produce Pre Registration House Officers (PRHOs) with improved communication skills? Med Teach 2006;28:264-9.

[8] Sullivan C, Ellison SR, Quaintance J, Arnold L, Godrey P. Development of a communication curriculum for emergency medicine residents. Teach Learn Med 2009;21:327-33.

[9] Cheng SY, Chen Walter, Huang CY, Chan CY, Li TC: A novel course for fostering systems-based practice competency among medical students. J Med Education 2011; 15: 96-105.

[10] Borges NJ, Navarro AM, Grover AC: Women physicians: choosing a career in academic medicine. Acad Med 2012;87:105-14

[11] Boyd JS, Clyne B, Reinert SE, Zink BJ: Emergency medicine career choice: a profile of factors and influences from the Association of American Medical Colleges (AAMC) graduation questionnaires. Acad Emerg Med 2009;16:544-9.

[12] Dodson TF, Webb AL: Why do residents leave general surgery? The hidden problem in today's programs. Curr Surg 2005;62:128-31.

[13] Trowbridge E, Hildebrand C, Vogelman B: Commitment to change in graduate medical education. Med Educ 2009; $43: 493$.

[14] Van Hoof TJ. CME planning series: article five of five, using commitment to change within educational activities. Conn Med 2009;73:161-3.

[15] Shershneva MB, Wang MF, Lindeman GC, et al: Commitment to practice change: an evaluator's perspective. Eval Health Prof 2010;33:256-75. 